\title{
Right- and left-sided colon cancer - clinical and pathological differences of the disease entity in one organ
}

\author{
Michal Mik, Maciej Berut, Lukasz Dziki, Radzislaw Trzcinski, Adam Dziki
}

Department of General and Colorectal Surgery, Medical University of Lodz, Lodz, Poland

Submitted: 10 November 2014

Accepted: 8 March 2015

Arch Med Sci 2017; 13, 1: 157-162

DOI: 10.5114/aoms.2016.58596

Copyright $\odot 2016$ Termedia \& Banach

\section{Abstract}

Introduction: Some researchers suggest that cancers located in the right vs. the left side of the colon are different and they can be regarded as distinct disease entities. The aim of this study was to analyze differences in clinical, epidemiological and pathological features of patients with right-sided (RCC) and left-sided (LCC) colon cancer.

Material and methods: One thousand two hundred and twenty-four patients were operated on due to colorectal cancer. A group of 477 patients (254 women, mean age $65.5 \pm 11$ for the whole group) with colon cancer was included (212 RCC vs. 265 LCC).

Results: Right colon cancer patients were older $(67.8 \pm 11.3$ vs. $63.2 \pm 11.2$; $p=0.0087)$. Left colon cancer patients underwent surgery for urgent indications more often $(17.0 \%$ vs. $8.5 \% ; p=0006)$. Tumor diameter was greater in the RCC group ( $55 \pm 60 \mathrm{~mm}$ vs. $38 \pm 21 \mathrm{~mm} ; p=0.0003$ ). Total number of removed lymph nodes was higher in the RCC group (11.7 \pm 6 vs. $8.3 \pm 5 ; p=$ $0.0001)$. Lymph node ratio was higher in the LCC group ( $0.45 \pm 0.28$ vs. 0.30 $\pm 0.25 ; p=0.0063$ ). We found a strong positive correlation between tumor diameter and the number of removed lymph nodes in the LCC group ( $r=$ 0.531).

Conclusions: These differences may result from the fact that RCC patients are diagnosed at an older age. The smaller number of removed lymph nodes in LCC patients may result in incorrect staging. It is still necessary to find other biological dissimilarities of adenocarcinoma located on different sides of the colon.

Key words: colon cancer, pathology, surgery, location, right-sided, leftsided.

\section{Introduction}

Over the past few years, there have been more and more studies evaluating the clinical differences between adenocarcinoma located in the right and left part of the colon. Proximal and distal segments of the colon have different embryologic origins. The segment extending from the cecum to the proximal two thirds of the transverse colon derives from the midgut. The segment comprising the distal third of the transverse colon to the upper anal canal derives from the hindgut. If we consider the distal transverse colon as the boundary between the right colon and left colon, the right colon includes the cecum, ascending colon, liver flexure, and trans-

\author{
Corresponding author: \\ Michal Mik MD, PhD \\ Department of General \\ and Colorectal Surgery \\ Medical University of Lodz \\ Plac Hallera 1 \\ 91-647 Lodz, Poland \\ Phone: +48 504048127 \\ E-mail: m.mik@wp.pl
}


verse colon, and the left colon includes the splenic flexure, descending colon and sigmoid colon. In the early 1990s Bufill proposed such a division, believing that apart from anatomic differences, there are also other differences in tumor biology and pathophysiology. Differences in the embryologic origin of colonic epithelium of proximal and distal segments may determine differences in susceptibility to environmental carcinogens. The knowledge of these differences might alter methods of treatment or principles of screening in patients with colon cancer [1]. Some researchers even claim that tumors located on the right side vs. the left side are so different from each other that they can be regarded as distinct disease entities of the same organ. It is believed that in the elderly and in women the tumor is more often located in the right colon and is greater in diameter at this location than in the left colon. There are also differences in the pathology and molecular features of the tumors [2-4]. Various clinical presentations and characteristics of distant metastases have been reported. Konopke et al. found that metastases of right sided tumors are localized predominantly in the right lobe of the liver but when the tumor is located in the left colon then liver metastases frequently occupy both liver lobes [5]. The reason for these differences is not fully understood. Some authors suggest that it may result from the fact that the right colon, left colon and rectum have different embryological origins [6]. Based on the results of these studies, some researchers suggest that colorectal adenocarcinoma can be divided into three distinct disease entities: cancer of the right colon, left colon and rectal cancer [7]. Knowing all the clinical differences we can alter screening procedures as well as methods of treatment in the subgroup of patients.

The aim of our study was to analyze differences in clinical, epidemiological and pathological features of patients with cancer tumors located in the right and left side of the colon.

\section{Material and methods}

The analysis included patients who underwent surgery in the Department of General and Colorectal Surgery, Medical University of Lodz in the period from 2009 to 2012. The patients were operated on both electively and also with urgent indications (within $48 \mathrm{~h}$ of admission). According to the location of the tumor the study group was divided into two subgroups: patients with cancer located in the right side of the colon - cecum, ascending colon and transverse colon cancers (RCC); and patients with cancer located in the left side of the colon - splenic flexure, descending colon and sigmoid colon cancers (LCC). The study was retrospective. We analyzed the data from the hospital database. The relationship between the location of the tumor, clinical and pathological features, severity of disease and early outcomes were evaluated. In the pathological analysis the following features were taken into account: pTNM classification, grading, lymph node ratio $(\mathrm{pN}+/ \mathrm{N}-$ the ratio of the number of cancerous lymph nodes to the total number of removed lymph nodes examined in the postoperative specimen).

\section{Statistical analysis}

Quantitative variables are presented as mean \pm standard deviation (SD). To analyze the relationship between the location of the tumor and the studied variables the $\chi^{2}$ test was used, and for continuous variables Student's $t$ test was used. Differences were considered statistically significant at $p$ less than 0.05. To evaluate the correlation between pathological variables we used Pearson's coefficient $(r)$. We considered $r$ values from -0.5 to 0.0 to indicate a weak negative correlation, $r$ values from 0.0 to 0.5 a weak positive correlation, $r$ values from -1.0 to -0.5 a strong negative correlation, and $r$ values from 0.5 to 1.0 a strong positive correlation. For statistical analysis we used software intended for non-commercial use: Free Statistics Software, Office for Research Development and Education, version 1.1.23-r7 [8].

\section{Results}

In the period 2009-2012, in the Department of General and Colorectal Surgery a total group of 1224 patients was operated on due to colorectal adenocarcinoma. For the current study we included a group of 477 patients (254 women, mean age $65.5 \pm 11$ for the whole group), with a tumor located in the colon. All patients included in the study underwent a resection procedure. In all the patients the severity of the disease (pathological staging) was assessed based on postoperative specimens. We excluded patients who underwent only palliative surgery (laparotomy, stoma or bypass anastomosis). In the study group we noted a slight majority of women, in both RCC and LCC groups. Patients from the RCC group admitted for surgery were significantly older than LCC patients: $67.8 \pm 11.3$ vs. $63.2 \pm 11.2 ; p=0.0087$. Patients from the RCC group also revealed significantly lower body mass index (BMI): $26.05 \pm 4.1 \mathrm{~kg} / \mathrm{m}^{2}$ vs. $28.85 \pm 3.9 \mathrm{~kg} / \mathrm{m}^{2} ; p=0.031$. Patients with LCC were significantly more likely to undergo surgery for urgent indications: $17.0 \%$ vs. $8.5 \% ; p=0006$.

We used the American Society of Anesthesiologists (ASA) scale in both groups of patients. We found no statistically significant differences, and the distribution of variables was also similar for the RCC and LCC ( $p=0.163)$. Other details of the study group are presented in Table I. 
We compared the pathological features of cancer between the groups. The tumor diameter was significantly greater in the RCC group $(55 \pm 60 \mathrm{~mm}$ vs. $38 \pm 21 \mathrm{~mm} ; p=0.0003)$. The number of lymph nodes with metastasis (positive lymph nodes) was assessed, and we found that in the RCC group the pathological stage of the tumor was significantly higher than in patients with LCC. In addition, we found that the total number of lymph nodes removed during surgery was also significantly higher in the RCC group than the LCC group (11.7 \pm 6 vs. $8.3 \pm 5 ; p=0.0001$ ). Pathological grading in the two groups of patients was significantly different. In the RCC group there were significantly more patients with $\mathrm{G} 1$ and $\mathrm{G} 3$ than in the LCC group $(16,7.5 \%$ vs. $7,2.7 \% ; 29,13.7 \%$ vs. $15,5.6 \% ; p=0.0002)$. The rest of the results comparing tumor pathology in the two groups are included in Table II.

In our study we also analyzed early results of treatment. Complications were divided into systemic and surgical - complications requiring reoperation. In the whole group of patients, a group of $47(9.8 \%)$ patients developed organ failures, mainly cardiac 17 (3.7\%). When we analyzed anastomotic leaks we observed difference with borderline significance between RCC and LCC. The leaks occured more frequently in RCC patients (12, 5.6\% vs. $6,2.3 \% ; p=0.053)$. Analysis of postoperative complications requiring reoperation showed that patients with RCC were also at significantly more risk $(23,10.8 \%$ vs. $15,5.7 \%$; $p=0.037)$. Details of the analysis are included in Table III.

We wanted to determine whether there is an association between the size of the primary tumor and the number of removed lymph nodes during surgery. In the RCC group the Pearson coefficient $(r=0.193)$ showed a weak positive correlation between these two variables. However, in the LCC group there was a strongly positive correlation $(r=0.531)$ (Figure 1).

Assessing the relationship between the growth of the tumor (its diameter) and the degree of spread to lymph nodes ( $\mathrm{pN}+$ ), we found a weakly negative correlation of these two features in patients with RCC. The larger the size of the tumor, the smaller was the number of positive lymph nodes $(r=-0.124)$. However, in the LCC group we found a weak positive correlation $(r=0.181)$. We observed a weak negative correlation between the diameter of the tumor and the lymph node ratio in both the RCC and LCC group ( $r=-0.125$ vs. $r=-0.155)$.

\section{Discussion}

Considering anatomical differences and different embryological origin of the right and left part of the colon, we can find different clinical features of the same disease. In many previously published studies the authors were looking for differences in the course of the disease, its pathophysiology, genetic basis and prognosis $[2,4,9,10]$. These differences may indicate the different ways of treatment of patients according to the location of the tumor in the colon. In our study, we focused on differences in epidemiological and pathological features and early results of treatment in patients operated on for colon cancer.

In our study group, we found that patients with RCC were significantly older than patients

Table I. Demographic characteristics of the studied group of patients

\begin{tabular}{|c|c|c|c|}
\hline Feature & $\operatorname{RCC}(n=212)$ & $\operatorname{LCC}(n=265)$ & $P$-value \\
\hline \multicolumn{4}{|l|}{ Gender (\%): } \\
\hline Male & $116(54.7)$ & $138(52.1)$ & 0.565 \\
\hline Female & $96(45.3)$ & $127(47.9)$ & \\
\hline Age, mean \pm SD [years] & $67.8 \pm 11.3$ & $63.2 \pm 11.2$ & $0.0087^{*}$ \\
\hline $\mathrm{BMI}$, mean $\pm \mathrm{SD}\left[\mathrm{kg} / \mathrm{m}^{2}\right]$ & $26.05 \pm 4.1$ & $28.85 \pm 3.9$ & $0.031^{*}$ \\
\hline \multicolumn{4}{|l|}{ ASA score (\%): } \\
\hline I & $3(1.4)$ & $13(4.9)$ & 0.163 \\
\hline II & $138(65.1)$ & $157(59.3)$ & \\
\hline III & $67(31.6)$ & $90(33.9)$ & \\
\hline IV & $4(1.9)$ & $5(1.9)$ & \\
\hline \multicolumn{4}{|l|}{ Mode of surgery (\%): } \\
\hline Elective & $194(91.5)$ & $220(83.0)$ & 0.006 \\
\hline Urgent & $18(8.5)$ & $45(17.0)$ & \\
\hline
\end{tabular}


Table II. Pathological characteristics of the tumor

\begin{tabular}{|c|c|c|c|}
\hline Feature & $\operatorname{RCC}(n=212)$ & LCC $(n=265)$ & $P$-value \\
\hline Tumor diameter, mean \pm SD [mm] & $55 \pm 60$ & $38 \pm 21$ & $0.0003^{*}$ \\
\hline Staging (pT) (\%): & & & 0.703 \\
\hline $\mathrm{T} 1$ & $6(2.8)$ & $8(3.0)$ & \\
\hline $\mathrm{T} 2$ & $55(25.9)$ & $80(30.2)$ & \\
\hline T3 & $132(62.3)$ & $151(57.0)$ & \\
\hline $\mathrm{T} 4$ & $19(9.0)$ & $26(9.8)$ & \\
\hline \multicolumn{4}{|l|}{ Staging $(\mathrm{pN})(\%)$ : } \\
\hline NO & $100(47.2)$ & $163(61.5)$ & 0.005 \\
\hline N1 & $69(32.5)$ & $58(21.9)$ & \\
\hline $\mathrm{N} 2$ & $43(20.3)$ & $44(16.6)$ & \\
\hline \multicolumn{4}{|l|}{ Metastases in lymph nodes (\%): } \\
\hline $\mathrm{N}(-)$ & $100(47.2)$ & $163(61.5)$ & 0.001 \\
\hline $\mathrm{N}(+)$ & $112(52.8)$ & $102(38.5)$ & \\
\hline \multicolumn{4}{|l|}{ Staging $(M)(\%)$ : } \\
\hline M1 & $39(18.4)$ & $54(20.4)$ & 0.587 \\
\hline MO & $173(81.6)$ & $211(79.6)$ & \\
\hline \multicolumn{4}{|l|}{ Grading: } \\
\hline G1 & $16(7.5)$ & $7(2.7)$ & 0.0002 \\
\hline $\mathrm{G} 2$ & $167(78.8)$ & $243(91.7)$ & \\
\hline $\mathrm{G3}$ & $29(13.7)$ & $15(5.6)$ & \\
\hline Number of removed lymph nodes, mean \pm SD & $11.7 \pm 6$ & $8.3 \pm 5$ & $0.0001^{*}$ \\
\hline Lymph node ratio & $0.30 \pm 0.25$ & $0.43 \pm 0.28$ & $0.0063^{*}$ \\
\hline
\end{tabular}

Table III. Early results of surgical treatment

\begin{tabular}{|lccc|}
\hline Type of complication & RCC $(n=212)$ & LCC $(n=265)$ & $P$-value \\
\hline Systemic (\%): & $5(2.4)$ & $12(4.5)$ & 0.204 \\
\hline Cardiac & $3(1.4)$ & $8(3.0)$ & 0.246 \\
\hline Pneumonia & $9(4.2)$ & $8(3.0)$ & 0.472 \\
\hline Urinary tract infection & 0 & $2(0.8)$ & - \\
\hline Thromboembolism & $17(8.0)$ & $30(11.3)$ & 0.229 \\
\hline Total & $3(1.4)$ & $4(1.5)$ & 0.933 \\
\hline Surgical (\%): & $2(0.9)$ & 0 & - \\
\hline Hemorrhage & $12(5.6)$ & $6(2.3)$ & 0.053 \\
\hline Intra-abdominal abscess & $1(0.4)$ & $3(1.1)$ & 0.431 \\
\hline Anastomotic leak & $5(2.4)$ & $2(2.2)$ & 0.147 \\
\hline Ileus & $23(10.8)$ & $15(5.7)$ & 0.037 \\
\hline \begin{tabular}{l} 
Exenteration \\
\hline Total
\end{tabular} & & \\
$\chi^{2}$ test. & & & \\
\hline
\end{tabular}


with LCC. This result is fully consistent with data from other papers $[2,4,6,11,12]$. Jess et al. found a nearly linear relationship between the age of operated patients and the location of the tumor. The older patients had a more proximal location. Patients with a tumor in the sigmoid colon were the youngest, and those with a tumor in the cecum were the oldest [6]. This fact probably can be explained by a delay in the diagnosis of cancer in the right side of the colon. Disease in the right colon can give more subtle symptoms than cancer located on the left side, which is often associated with pain. The time from the beginning of the development of cancer to overt clinical symptoms is estimated as 4.5 to 5.8 years [13]. Another cause of the difference in age of patients with RCC and LCC qualified for surgery seems to be lower accuracy of colonoscopy for tumors in the right side of the colon (mainly the cecum). We did not analyze preoperative endoscopies [14].

In our study we also noted a difference in the size of the tumor, and we revealed that the diameter of the tumor on the right side is significantly larger than on the left side. These results are in accordance with other studies [11]. The wider lumen of the right colon and more frequent flat tumor growth in this location allow it to achieve a larger size when it is still clinically asymptomatic [3]. This fact is related to another result reported in our paper. Patients with RCC required urgent surgery significantly less frequently than patients with LCC. This is probably due to the fact that patients with LCC develop symptoms of bowel obstruction more often, and it can be an indication for urgent intervention. We noted differences in the distribution of pathological grading of the tumor. The differences were related to each of the three tumor stages. It may testify to existing but not yet known differences in the biology of the tumor which are depended on its location in the colon.

In some studies the authors found that patients with RCC suffer from more comorbidities than patients with LCC; the differences were clear when assessing the ASA score [4]. It was noted that ASA $\geq \mathrm{III}$ is most common in patients with a tumor located in the liver flexure and the transverse colon [15]. In our study, we confirmed no such disparities in the distribution of ASA score; moreover, the distribution according to ASA score in both groups was quite similar.

We found that the location of the tumor had no effect on the incidence of systemic complications. Anastomotic leak was the only clinical feature occurring in patients with RCC slightly more often. It is hard to explain the background of the result and answer the question why in the subgroup of our patients the complication occurred more often. In addition, taking into account all surgical complications, it turned out that patients with RCC were at

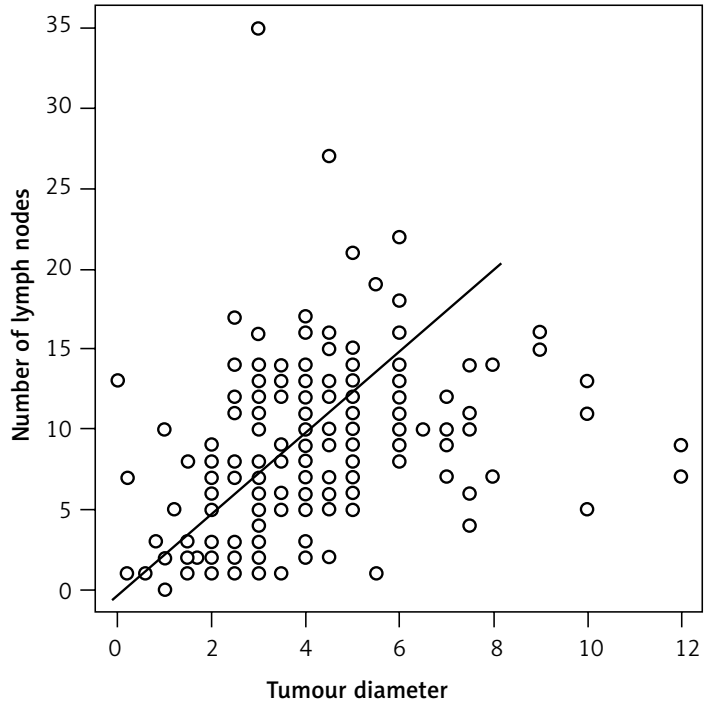

Figure 1. Correlation between tumor diameter and number of removed lymph nodes in left side of colon

higher risk of reoperations than patients with LCC. This result is really surprising, since almost all patients from the RCC group were operated on electively and their general condition was assessed at a similar level (by ASA score) in comparison with patients with LCC.

In the paper we tried to analyze the characteristics and distribution of the lymph nodes. We found that the average number of lymph nodes removed during the operation was significantly higher in the RCC group than in the LCC group. The fact that the number of harvested lymph nodes in the specimens was an average of less than 12 is quite difficult to clearly explain. The minimum number of evaluated lymph nodes for the proper tumor staging should be at least 12 . The number is always based on both the quality of surgery and the quality of pathological examination. In our series it is likely also the result of these two variables.

In our study we also found that the severity of the disease (number of positive lymph nodes) was significantly higher in patients with RCC compared to LCC. It may be the result of a longer time from the beginning of carcinogenesis to diagnosis of cancer in the RCC group. Our results are in accordance with data published in other papers [7, 11].

For several years, it has been believed that the lymph node ratio (the number of lymph nodes with metastases/the number of all removed lymph nodes in the specimen) has a prognostic value in many cancers of the gastrointestinal tract including colon cancer [16]. In our study, we did not analyze factors influencing the survival rate. However, we noted a statistically significant difference in the lymph node ratio between two studied subgroups. The ratio was higher in patients with LCC compared to the RCC group. This may be as- 
sociated with worse prognosis in this group of patients from our study. Our results are not fully in accordance with some published data, since the lymph node ratio was higher for RCC patients [11].

We analyzed the correlation between tumor size, lymph node ratio and other variables associated with pN stage. The only strong positive correlation was found between the increase of the diameter of the tumor and the number of removed lymph nodes during surgery in the LCC patients. In other investigated relationships the correlations were weakly positive or weakly negative. It is difficult to draw clear conclusions from these relationships; they probably require further analysis of correlations associated with overall survival time or disease-free survival time.

We realize that a weak point of the study was the lack of analysis of the survival time. The analysis would be helpful to find possible risk factors that can affect late results. However, in other published studies such an analysis was not carried out either $[15,17]$. In our opinion, the homogeneity of the data collected for analysis is a strong point of our study.

In conclusion, cancers of the right and left side of the colon vary according to clinical and pathological features. In our study, cancer of the right side of the colon was clinically more advanced at diagnosis.

These differences may result from the fact that patients with cancer located on the right side are diagnosed at an older age. Therefore one should pay particular attention to all subtle symptoms appearing in patients.

The smaller number of removed lymph nodes in patients with cancer on the left side in our series may affect the incorrect staging and thus long-term outcomes.

In our opinion, due to these differences, it is still necessary to find other biological dissimilarities of adenocarcinoma located on different sides of the colon.

\section{Conflict of interest}

The authors declare no conflict of interest.

\section{References}

1. Bufill JA. Colorectal cancer: evidence for distinct genetic categories based on proximal or distal tumor location. Ann Intern Med 1990; 113: 779-88.

2. Saltzstein SL, Behling CA. Age and time as factors in the left-to-right shift of the subside of colorectal adenocarcinoma: a study of 213,383 cases from the California Cancer Registry. J Clin Gastroenterol 2007; 41: 173-7.

3. Nawa T, Kato J, Kawamoto H, et al. Differences between right- and left-sided colon cancer in patient characteristics, cancer morphology and histology. J Gastroenterol Hepatol 2008; 23: 418-23.
4. Benedix F, Meyer F, Kube R, Gastinger I, Lippert H. Rightand left-sided colonic cancer - different tumour entities. Zentralbl Chir 2010; 135: 312-7.

5. Konopke R, Distler M, Ludwig S, Kersting S. Location of liver metastases reflects the side of the primary colorectal carcinoma. Scand J Gastroenterol 2008; 43: 192-5

6. Jess P, Hansen IO, Gamborg M, Jess T; Danish Colorectal Cancer Group. A nationwide Danish cohort study challenging the categorisation into right-sided and left-sided colon cancer. BMJ Open 2013; 3 pii: e002608. doi: 10.1136/bmjopen-2013-002608.

7. Benedix F, Schmidt U, Mroczkowski P, Gastinger I, Lippert H, Kube R; Study Group “Colon/Rectum Carcinoma (Primary Tumor)". Colon carcinoma - classification into right and left sided cancer or according to colonic subside? Analysis of 29,568 patients. Eur J Surg Oncol 2011; 37: 134-9.

8. Wessa P. Free Statistics Software, Office for Research Development and Education, version 1.1.23-r7, 2014; URL http://www.wessa.net/.

9. Charlier P, Huynh-Charlier I, Poupon J, et al. A glimpse into the early origins of medieval anatomy through the oldest conserved human dissection (Western Europe, 13(th) c. A.D.). Arch Med Sci 2014; 12: 366-73.

10. Maruta M, Kotake K, Maeda K. Colorectal cancer in Japan. Rozhl Chir 2007; 86: 618-21.

11. Christodoulidis G, Spyridakis M, Symeonidis D, Kapatou K, Manolakis A, Tepetes K. Clinicopathological differences between right- and left-sided colonic tumors and impact upon survival. Tech Coloproctol 2010; 14: S45-7.

12. Benedix F, Kube R, Meyer F, Schmidt U, Gastinger I, Lippert H; Colon/Rectum Carcinomas (Primary Tumor) Study Group. Comparison of 17,641 patients with rightand left-sided colon cancer: differences in epidemiology, perioperative course, histology, and survival. Dis Colon Rectum 2010; 53: 57-64.

13. Brenner H, Altenhofen L, Katalinic A, Lansdorp-Vogelaar I, Hoffmeister M. Sojourn time of preclinical colorectal cancer by sex and age: estimates from the German national screening colonoscopy database. Am J Epidemiol 2011; 174: 1140-6.

14. Singh $H$, Nugent Z, Demers AA, Bernstein CN. Rate and predictors of early/missed colorectal cancers after colonoscopy in Manitoba: a population-based study. Am J Gastroenterol 2010; 105: 2588-96.

15. Hansen IO, Jess P. Possible better long-term survival in left versus right-sided colon cancer - a systematic review. Dan Med J 2012; 59: A4444.

16. Sabbagh C, Mauvais F, Cosse C, et al. A lymph node ratio of $10 \%$ is predictive of survival in stage III colon cancer: a French Regional Study. Int Surg 2014; 99: 344-53.

17. Meza R, Jeon J, Renehan AG, Luebeck EG. Colorectal cancer incidence trends in the United States and United kingdom: evidence of right- to left-sided biological gradients with implications for screening. Cancer Res 2010; 70: 5419-29. 